\title{
Prevalence of oxygen desaturation and use of oxygen at home in adults at sea level and at moderate altitude
}

\author{
R. Perez-Padilla*, L. Torre-Bouscoulet*, A. Muiño\#, M.N. Marquez\# ${ }^{\#}$ M.V. Lopez ${ }^{\#}$, \\ M.M. de Oca , C. Talamo and A.M.B. Menezes ${ }^{+}$, on behalf of the Proyecto \\ Latinoamericano de Investigacion en Obstruccion Pulmonar (PLATINO) group
}

ABSTRACT: The aim of this study was to determine the prevalence of oxygen desaturation in adults aged $\geqslant \mathbf{4 0}$ yrs as altitude above sea level increases.

A population-based, cross-sectional study with a multistage cluster sampling of 1,063 subjects from metropolitan Mexico City (Mexico; 2,240 m above sea level), 1,357 from Caracas (Venezuela; $950 \mathrm{~m}$ ) and 943 from Montevideo (Uruguay; $35 \mathrm{~m}$ ). The mean of six measurements of arterial oxygen saturation $\left(\mathrm{SP}, \mathrm{O}_{2}\right)$ was estimated using a pulse oximeter.

Mean $\mathrm{SP}, \mathrm{O}_{2}$ decreased with altitude. No subject from Montevideo had a mean $\mathrm{SP}, \mathrm{O}_{2} \leqslant 88 \%$. Prevalence of subjects with $\mathrm{SP}, \mathrm{O}_{2} \leqslant 88 \%$, a common criterion used for oxygen prescription, was $1.0 \%$ in Caracas and $6.0 \%$ in Mexico City. Additional predicting factors for hypoxaemia in multiple regression models were age, body mass index and a low forced expiratory volume in one second as a percentage of the predicted value. In Mexico City and Caracas, $<10 \%$ of the hypoxaemic subjects reported use of domiciliary oxygen, whereas at least half of the subjects reporting use of oxygen at home had a resting $\mathrm{SP}, \mathrm{O}_{2}>88 \%$.

In conclusion, the prevalence of hypoxaemia was closely related to altitude. Priorities for oxygen prescription must be defined in moderate altitudes because it is unfeasible to provide it to all subjects fulfilling the criteria commonly used.

KEYWORDS: Altitude, gas exchange, hypoxia, oxygen saturation, Proyecto Latinoamericano de Investigacion en Obstruccion Pulmonar (PLATINO) study

hronic hypoxaemia produces several adverse health effects, including pulmonary hypertension, cor pulmonale and death $[1,2]$. Patients with chronic obstructive pulmonary disease (COPD) and hypoxaemia defined as an arterial oxygen tension $\left(\mathrm{Pa}, \mathrm{O}_{2}\right)$ $\leqslant 7.33 \mathrm{kPa}(55 \mathrm{mmHg}$, arterial oxygen saturation $\left(\mathrm{SP}, \mathrm{O}_{2}\right)$ of $\left.88 \%\right)$, or from $7.33-7.87 \mathrm{kPa}(55-$ $59 \mathrm{mmHg}$ ) with cor pulmonale or polycythaemia have a reduced survival rate that improves with oxygen therapy [3-5]. Altitude is one of the major determinants of hypoxaemia, although age, obesity and lung disease also contribute $[1,2,6,7]$. Prevalence of hypoxaemia in Mexico City, defined as a $\mathrm{Pa}_{1} \mathrm{O}_{2}<7.33 \mathrm{kPa}(55 \mathrm{mmHg})$, was previously estimated to be between $0.9-3.4 \%$ using theoretical models of $\mathrm{Pa}_{1} \mathrm{O}_{2}$ decrease with ageing and altitude. [8]. A widely used criteria for supplementary oxygen prescription is an $S \mathrm{P}, \mathrm{O}_{2} \leqslant 88 \%$ [9]. The purpose of this study was to estimate the prevalence of oxygen desaturation and its predictors in adults residing at sea level and at a moderate altitude (950 and 2,240 m). Hypoxaemic subjects are also potential users of home oxygen services, an expensive treatment [10] that has to be optimised in the present economic climate of cost containment.

\section{METHODS}

Ethical approval was obtained from the ethics committee of the institutions involved in the study (National Institute of Respiratory Diseases, Mexico City, Mexico; University of the Republic, Montevideo, Uruguay; Hospital Universitario de Caracas, Universidad Central de Venezuela, Caracas, Venezuela; and Federal University of Pelotas, Pelotas, Brazil) and all subjects signed a written consent form.

The Proyecto Latinoamericano de Investigacion en Obstruccion Pulmonar (PLATINO) project was planned to estimate the prevalence of COPD in five Latin-American cities, using a multistage cluster sampling, to obtain a minimum of 800
AFFILIATIONS

${ }^{*}$ National Institute of Respiratory Diseases, Mexico City, Mexico. \#University of the Republic, Faculty of Medicine, Montevideo, Uruguay. "Pulmonary Division, Hospital Universitario de Caracas, Universidad Central de Venezuela, Caracas, Venezuela.

+Federal University of Pelotas,

Pelotas, Brazil.

CORRESPONDENCE

R. Perez-Padilla

Instituto Nacional de Enfermedades Respiratorias

Tlalpan 4502

DF 14080

Mexico

Fax: 525556668640

E-mail: perezpad@servidor.unam.mx

Received:

June 272005

Accepted after revision

October 212005

SUPPORT STATEMENT

This study was supported in part by a research grant from Boehringer-

Ingelheim, Germany 
noninstitutionalised subjects per city aged $\geqslant 40$ yrs. The methods of the PLATINO study have been published [11], as well as the prevalence of COPD in the survey [12].

The subjects answered a respiratory symptoms questionnaire, including sections of the American Thoracic Society (ATS) Division of Lung Diseases questionnaire, the European Community Respiratory Health Survey II, the Lung Health Study and Short Form Health Survey with 12 items (SF-12®) Health Survey [11, 12]. Duplicate measurements of body weight (scale HS-301; Tanita Corporation, Tokyo, Japan) and height (208 stadimeter; Seca Corporation, Hamburg, Germany) were made, reporting the averages. Standardisation of measurements were made before the study [13]. Spirometric testing (Easy-One; ndd Medizintechnik AG, Zürich, Switzerland) was included, following the ATS recommendations [14] and reference values for MexicanAmericans [15].

$\mathrm{SP}, \mathrm{O}_{2}$ was measured using a pulse oximeter (Onyx 9500; Nonin Medical Inc., Plymouth, MN, USA) in Mexico City $(2,240 \mathrm{~m}$ above sea level), Caracas ( $950 \mathrm{~m}$ ) and Montevideo (35 m), but not in Santiago (Chile; $547 \mathrm{~m}$ ) or Sao Paulo (Brazil; $800 \mathrm{~m}$ ). The oximeter was attached to the subject's right index finger and all subjects were seated and breathing room air when the measurement was taken. The average of six measurements taken at 10-s intervals [16] was reported, on the condition that a good pulse signal was present (identified by a green flashing light in the device). The accuracy of five of the pulse oximeters used in the study was tested on all five fingers of one hand of 96 patients whose arterial blood gas was analysed by the pulmonary laboratory of the National Institute of Respiratory Diseases in Mexico City (mean $\pm \mathrm{SD}$ arterial oxygen saturation $\left(\mathrm{Sa}, \mathrm{O}_{2}\right)$ of $\left.87.2 \pm 11 \%\right)$. The mean error of $\mathrm{SP}, \mathrm{O}_{2}$ compared with $\mathrm{Sa}, \mathrm{O}_{2}$ of a simultaneous arterial blood sample was $0.28 \%(3.09 \%$ $\mathrm{SD})$ and the concordance correlation coefficient between the two measurements was 0.94 (95\% confidence interval (CI)
0.93-0.95). The concordance coefficient among instruments was $>0.95$ and that of each instrument compared with the mean of the five was $>0.98$.

Altitude was estimated four times in each zone studied in Mexico City and Caracas using an electronic altimeter 42, Altimatic (BARIGO Barometerfabrik GmbH, VillingenSchwenningen, Germany), and the average reported. In Montevideo, changes in altitude are minimal in the metropolitan area, as it ranges from 1-100 m above sea level.

Sampling design was taken into account in descriptive statistics and regression models by using the "survey" commands of the statistical package. To identify factors associated with $\mathrm{SP}_{\mathrm{O}} \mathrm{O}_{2}$, regression models, including age, sex, body mass index (BMI), altitude, current or past smoking, forced expiratory volume in one second (FEV1), as a percentage of predicted values and the interaction terms of altitude, were fitted with age, BMI, FEV1 \% pred and sex. Oxygen desaturation was defined as an $\mathrm{SP}, \mathrm{O}_{2} \leqslant 88 \%$, a common criterion for domiciliary oxygen prescription [9]. Impact of oxygen desaturation on health-related quality of life was evaluated by the SF-12 ${ }^{\circledR}$ physical score and mental score [17], adjusted by age, sex, lung function, BMI and level of education.

\section{RESULTS}

Final participation rate, including questionnaires, pulse oximetry and spirometry, was 73.2, 70 and $78 \%$ in Mexico City, Caracas and Montevideo, respectively. Anthropometric data, pulmonary function, oxygen saturation and smoking status of the subjects included in each city are shown in table 1. The final number of participants were: in Mexico City 1,063 , of whom 1,052 had $\mathrm{SP}, \mathrm{O}_{2}$ measured (626 females and 426 males); 943 in Montevideo, of whom 843 had $\mathrm{SP}_{2} \mathrm{O}_{2}$ measured (505 females and 338 males); and 1,357 from Caracas all of which had $\mathrm{SP}_{\mathrm{O}} \mathrm{O}_{2}$ measured (872 females

TABLE 1 General characteristics of population by sex and city

\begin{tabular}{|c|c|c|c|c|c|c|}
\hline \multirow[t]{2}{*}{ Subjects } & \multicolumn{2}{|c|}{ Mexico City ${ }^{\#}$} & \multicolumn{2}{|c|}{ Caracas } & \multicolumn{2}{|c|}{ Montevideo $^{+}$} \\
\hline & Female & Male & Female & Male & Female & Male \\
\hline Age yrs & $55.4 \pm 0.52$ & $56.4 \pm 0.69$ & $55.2 \pm 0.40$ & $55.7 \pm 0.52$ & $60.9 \pm 0.65$ & $59.0 \pm 0.61$ \\
\hline$B M I \mathrm{~kg} \cdot \mathrm{m}^{-2}$ & $29.5 \pm 0.27$ & $27.7 \pm 0.18$ & $27.6 \pm 0.21$ & $26.9 \pm 0.21$ & $28.7 \pm 0.30$ & $27.5 \pm 0.28$ \\
\hline $\mathrm{SP}, \mathrm{O}_{2} \%$ & $92.2 \pm 0.19$ & $92.3 \pm 0.17$ & $95.7 \pm 0.09$ & $95.2 \pm 0.12$ & $97.5 \pm 0.06$ & $97.0 \pm 0.07$ \\
\hline FVC \% pred & $99.3 \pm 0.69$ & $99.5 \pm 0.91$ & $96.6 \pm 0.71$ & $93.9 \pm 0.71$ & $101.1 \pm 0.72$ & $102.5 \pm 0.79$ \\
\hline $\mathrm{FEV}_{1} / \mathrm{FVC}$ & $81.1 \pm 0.30$ & $78.6 \pm 0.40$ & $78.9 \pm 0.25$ & $77.5 \pm 0.48$ & $78.0 \pm 0.34$ & $74.7 \pm 0.48$ \\
\hline Current smokers $\%^{\S}$ & $16.7 \pm 0.01$ & $38.2 \pm 0.02$ & $25.4 \pm 0.01$ & $34.0 \pm 0.02$ & $24.3 \pm 0.02$ & $33.4 \pm 0.02$ \\
\hline All subjects pack-yrs & $1.0 \pm 0.23$ & $4.5 \pm 0.71$ & $3.2 \pm 0.60$ & $8.9 \pm 0.74$ & $3.2 \pm 0.53$ & $16.0 \pm 1.77$ \\
\hline Smokers pack-yrs & $9.9 \pm 1.7$ & $15.6 \pm 1.7$ & $13.8 \pm 2.3$ & $23.2 \pm 1.7$ & $17.0 \pm 2.0$ & $37.4 \pm 3.1$ \\
\hline
\end{tabular}

Data are presented as mean $\pm \mathrm{SE}$, unless otherwise indicated. BMl: body mass index; $\mathrm{SP}, \mathrm{O}_{2}$, arterial oxygen saturation (as measured by a pulse oximeter); FEV1: forced expiratory volume in one second; \% pred: percentage of that predicted by HaNKINSON et al. [15]; FVC: forced vital capacity. ${ }^{*}: \mathrm{n}=1052 ;{ }^{\bullet}: \mathrm{n}=1357^{+}: \mathrm{n}=843 ;{ }^{\S}:$ for current smokers, the numbers are presented as prevalence $\pm \mathrm{SE}$. 


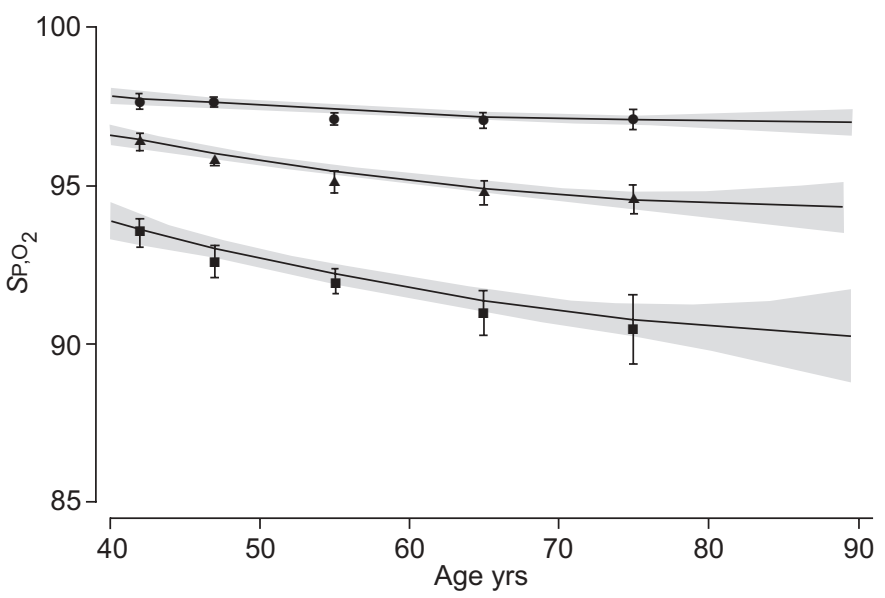

FIGURE 1. Oxygen saturation by city and age. Population means are depicted

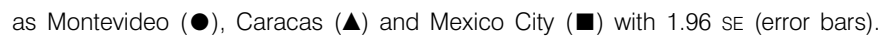
Lines and shadows represent the means and $95 \%$ confidence intervals, respectively estimated by a quadratic equation that fits the data well. $\mathrm{SP}, \mathrm{O}_{2}$ : arterial oxygen saturation.

and 485 males). The mean \pm SD age was $55.9 \pm 12,60.2 \pm 13$ and $55.4 \pm 11$ yrs in Mexico City, Montevideo and Caracas, respectively.

Oxygen saturation in Mexico City (2,240 m above sea level) was lower than in Caracas ( $950 \mathrm{~m}$ ) and Montevideo (35 m), but in the three cities it decreased with age (fig. 1). The decrease in $\mathrm{SP}, \mathrm{O}_{2}$ with age increased with altitude, but tended to reach a plateau in older subjects (fig. 1). $\mathrm{SP}, \mathrm{O}_{2}$ also decreased similarly with increasing obesity in the three cities (fig. 2). As the altitude of the city increased, the distribution of $\mathrm{SP}_{2} \mathrm{O}_{2}$ was displaced towards lower saturations, but, in addition, became wider (the SD of the distribution increased significantly) and left skewed, showing a longer tail of lower $\mathrm{SP}, \mathrm{O}_{2}$ values (fig. 3). None of the subjects from Montevideo had an $\mathrm{SP}, \mathrm{O}_{2} \leqslant 88 \%$. However, 13 subjects in Caracas (0.96\%, 95\% CI: 0.6-1.3) and 63 in Mexico City, $\left(6.0 \%\right.$, 95\% CI: 4.5-7.5) had an $\mathrm{SP}, \mathrm{O}_{2} \leqslant 88 \%$.

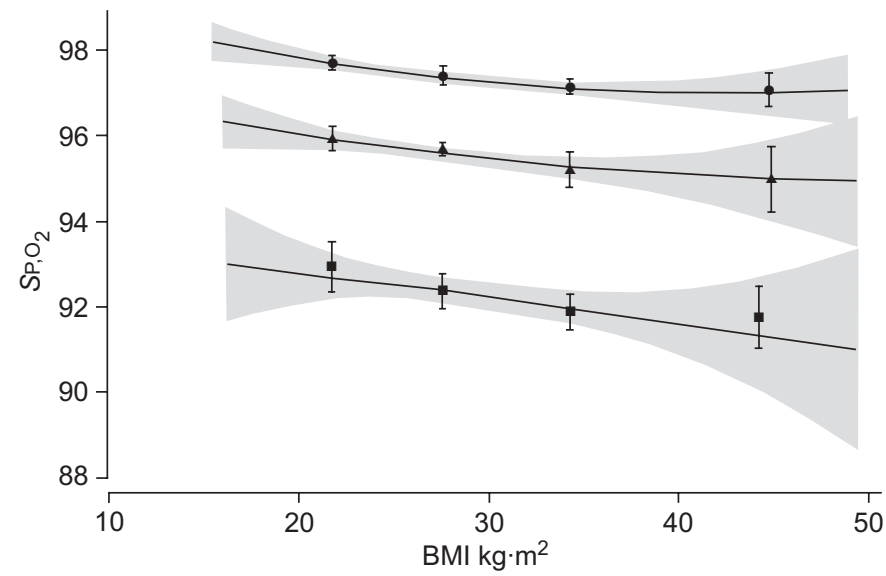

FIGURE 2. Oxygen saturation by city and body mass index (BMI). Population means are depicted as Montevideo $(\bullet)$, Caracas $(\boldsymbol{\Lambda})$ and Mexico City $(\boldsymbol{\square})$ with 1.96 SE (range bars). Lines and shadows represent the means and 95\% confidence intervals, respectively estimated by a quadratic equation that fits the data well. $\mathrm{SP}, \mathrm{O}_{2}$ : arterial oxygen saturation.

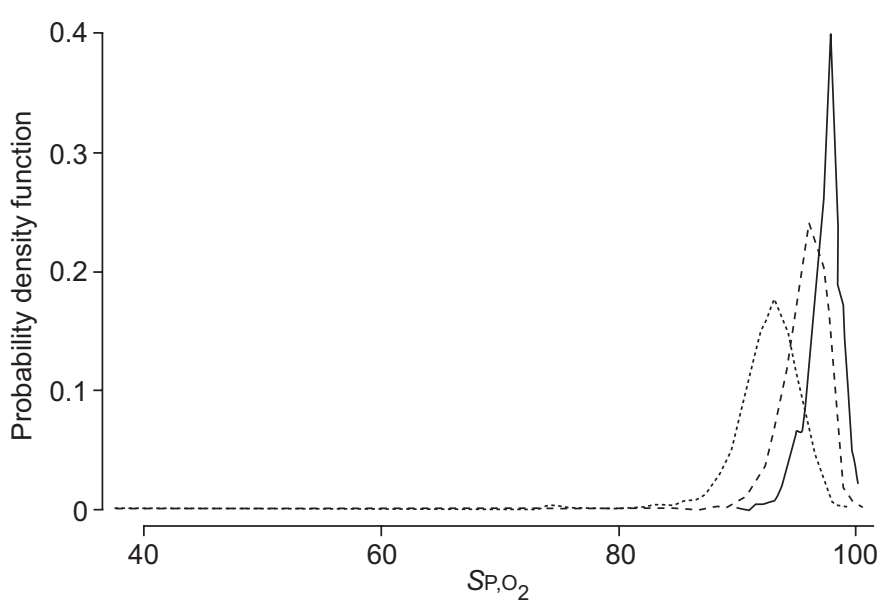

FIGURE 3. Population distribution of arterial oxygen saturation $\left(\mathrm{SP}, \mathrm{O}_{2}\right)$ measured by pulse oximetry. The population distribution is shown as the probability function, (the probability that a given $\mathrm{SP}, \mathrm{O}_{2}$ is found in the population). ........... Mexico City; ------: Caracas; —_: Montevideo

Prevalence of oxygen desaturation increased with age (table 2). In Mexico City, $10(0.9 \%)$ subjects reported the use of oxygen, five of whom had an $\mathrm{S} P, \mathrm{O}_{2}>88 \%$. In Caracas, four $(0.3 \%)$ subjects reported the use of oxygen, three of whom had an $\mathrm{SP}, \mathrm{O}_{2}>88 \%$. Only $8 \%$ of subjects with $\mathrm{SP}, \mathrm{O}_{2} \leqslant 88 \%$ reported the use of oxygen at home in Mexico City and Caracas. Note that the population estimates for the study are stratified by age.

Variables associated significantly with $\mathrm{SP}_{2} \mathrm{O}_{2}$ in multiple regression models were age, $\mathrm{BMI}, \mathrm{FEV} 1$ as a $\%$ pred values and altitude. Cumulative smoking expressed in pack-yrs had a small additional negative impact on $\mathrm{SP}_{2} \mathrm{O}_{2}$, but not current smoking. Table 3 shows the multiple regression equations for

\begin{tabular}{|c|c|c|c|}
\hline \multirow[t]{2}{*}{ TABLE 2} & \multicolumn{3}{|c|}{$\begin{array}{l}\text { Number of participants and percentage with } \\
\text { oxygen desaturation, stratified by age and city }\end{array}$} \\
\hline & Mexico City $\#$ & Caracas & Montevideo \\
\hline \multicolumn{4}{|l|}{ Subjects } \\
\hline $40-45$ yrs & 223 & 284 & 103 \\
\hline$>45-50$ yrs & 351 & 478 & 232 \\
\hline$>50-60$ yrs & 238 & 302 & 211 \\
\hline$>60-70$ yrs & 155 & 203 & 167 \\
\hline$>70 \mathrm{yrs}$ & 85 & 90 & 130 \\
\hline Total & 1,052 & 1,357 & 843 \\
\hline \multicolumn{4}{|c|}{ Subjects with $\mathrm{SP}, \mathrm{O}_{2} \leqslant 88 \%$} \\
\hline $0-45$ yrs & $2.2(1.0-5.1)$ & $0.7(0.2-2.9)$ & 0 \\
\hline$>45-50$ yrs & $3.4(2.0-5.7)$ & $0.4(0.11-1.58)$ & 0 \\
\hline$>50-60$ yrs & $5.0(2.7-9.3)$ & $1.0(0.3-2.9)$ & 0 \\
\hline$>60-70$ yrs & $12.9(7.6-21.1)$ & $2.0(0.7-5.1)$ & 0 \\
\hline$>70$ yrs & $16.5(9.5-27.1)$ & $2.2(0.6-7.8)$ & 0 \\
\hline Total & $6.0(4.6-7.7)$ & $1.0(0.6-1.5)$ & 0 \\
\hline
\end{tabular}

Data are presented as $\mathrm{n}$ or $\mathrm{n}$ (95\% confidence interval). SP, $\mathrm{O}_{2}$ : arterial oxygen saturation (measured by pulse oximetry). \#: Ten subjects reported home oxygen use; $\bullet$ : four subjects reported home oxygen use. 
each city and for the three cities as a group. The latter permits a linear interpolation of $\mathrm{SP}, \mathrm{O}_{2}$ for other altitudes. For example, to obtain a predicting equation for $2,240 \mathrm{~m}$, altitude was replaced by $2.24(\mathrm{~km})$ in the three cities equation. The resulting equation was very similar, but not identical, to that obtained with Mexico City data, as several altitudes were recorded in the city, and the overall equation was weighted by data from the other two cities. Coefficients for FEV1 \% pred and age were higher in Mexico City than at sea level.

To better describe the adverse impact of ageing and obesity on oxygenation, additional regression models were fitted, including age and BMI as categorical variables, adjusted by FEV1 \% pred and sex. Compared with subjects with BMI $\leqslant 25$, obesity $\left(\mathrm{BMI}>30 \mathrm{~kg} \cdot \mathrm{m}^{-2}\right)$ was associated with a change in $\mathrm{SP}, \mathrm{O}_{2}$ of $-1.3 \%(95 \% \mathrm{CI}:-0.6--2.0)$ in Mexico City, of $-0.6 \%$ $(-0.2--1.1)$ in Caracas and of $-0.6 \%(-0.3--0.8)$ in Montevideo. Compared with subjects $<45$ yrs of age, subjects $>65$ yrs had an $\mathrm{SP}, \mathrm{O}_{2}$ of $-2.8 \%(-2.0--3.5),-1.7 \%(-1.5--2.0)$ and $-0.5 \%(-0.2--0.9)$ in Mexico City, Caracas and Montevideo, respectively.

Significant predictors of hypoxaemia $\left(\mathrm{SP}_{\mathrm{P}} \mathrm{O}_{2} \leqslant 88 \%\right)$ in a multivariate logistic regression model were age, obesity, altitude, pack-yrs of smoking and a low FEV1 \% pred. The same predictors applied for $\mathrm{SP}, \mathrm{O}_{2}$ as a continuous variable. Subjects aged $>75 \mathrm{yrs}$ had an increased risk of oxygen desaturation (odds ratio (OR): $3.3,95 \% \mathrm{CI}$ : 1.6-6.9), as well as subjects with a BMI $>30 \mathrm{~kg} \cdot \mathrm{m}^{-2}$ (OR: $\left.1.8,95 \% \mathrm{CI}: 1.1-3.1\right)$, those with medical diagnosis of COPD (OR: 6.1, 95\% CI: 1.7-22.0) and residents of higher altitude (OR: 7.5, 95\% CI: 4.6 to 12.2 for each $\mathrm{km}$ of altitude above sea level). However, only $25 \%$ of the variation in hypoxaemia and $38 \%$ of variation of $\mathrm{SP}, \mathrm{O}_{2}$ was explained by the multivariate models, emphasising the need to measure $\mathrm{SP}_{\mathrm{P}} \mathrm{O}_{2}$.

$\mathrm{SP}, \mathrm{O}_{2}$ correlated with the physical scale but not with the mental scale of SF-12 ${ }$ questionnaire. Subjects with $\mathrm{SP}, \mathrm{O}_{2} \leqslant 88 \%$ had a lower SF-12® score in the physical scale, even when adjusting by age, BMI, sex, FEV1 \% pred, level of education and altitude above sea level (-2.4 points, 95\% CI: $-0.6--4.3)$.

\section{DISCUSSION}

The current study is the first description of the distribution of oxygen saturation in representative samples of large populations. As altitude increases, there is a reduction in mean $\mathrm{SP}, \mathrm{O}_{2}$ but, in addition, the distribution becomes wider and deviates from normality due to an enlarging tail towards lower saturations. Hypoxaemia was estimated previously for the Mexican population, based on the alveolar gas equation, altitude and age [8], although the model did not include obesity or lung disease. However, the model did not predict the low oxygen saturations observed in the studied population. In addition, concordance of measured and predicted oxygen desaturation from the model was very poor for individuals.

An $\mathrm{SP}, \mathrm{O}_{2}$ of $88 \%$ corresponds to a $\mathrm{Pa}_{2} \mathrm{O}_{2}$ of $7.33 \mathrm{kPa}(55 \mathrm{mmHg})$, a limit frequently used to prescribe home oxygen [3-5] and also separating a group with decreased survival in COPD $[3,4$, 5]. Approximately $6 \%$ of adults $>40 \mathrm{yrs}$ in Mexico City (a quarter of million people) and $0.96 \%$ in Caracas $(\sim 8,000$ subjects) were hypoxaemic by this definition, and would require oxygen at home if the measurement reflects the usual status of the patient. Exposure to altitude is important in LatinAmerica, either as a permanent residence or in transient visits. For example, in Mexico, half of the population resides $>1,500 \mathrm{~m}$ [8], and in Peru one-third lives $>2,500 \mathrm{~m}$ [18].

The adverse effects of age, obesity and lung disease on oxygenation are well known [1, 6, 7, 9]. However, altitude was the most important determinant of low oxygen saturation because it was only present in subjects from Mexico City and Caracas, despite the fact that the population in Montevideo was significantly older and had a higher prevalence of airflow obstruction.

In the present study, oxygen was used inappropriately, very little when needed and often without a clear need. Only $8 \%$ of hypoxaemic subjects $\left(\mathrm{SP}, \mathrm{O}_{2} \leqslant 88 \%\right)$ reported using oxygen at home, whereas half of the people receiving oxygen at home in Mexico City and three-quarters in Caracas were not hypoxaemic by definition. According to current indications, patients with nocturnal desaturation or hypoxaemia induced by

\section{TABLE 3 Regression equations for arterial oxygen saturation $\left(\mathrm{SP}, \mathrm{O}_{2}\right)$ measured by pulse oximetry}

\begin{tabular}{|c|c|c|c|c|c|c|c|}
\hline Subjects & Intercept & $\begin{array}{c}\text { Age } \\
\text { coefficient }^{\#}\end{array}$ & $\begin{array}{c}\text { BMI } \\
\text { coefficient }{ }^{\#}\end{array}$ & $\begin{array}{l}\text { FEV } 1 \% \text { pred } \\
\text { coefficient }^{\#}\end{array}$ & $\begin{array}{c}\text { Sex } \\
\text { coefficient }\end{array}$ & MSE & $\mathbf{R}^{2}(\%)$ \\
\hline Montevideo & 99.36 & -0.20 & -0.43 & 0.07 & -0.58 & 1.3 & 10.86 \\
\hline Caracas & 97.62 & -0.55 & -0.48 & 0.27 & -0.38 & 2.3 & 11.94 \\
\hline Mexico City & 96.03 & -0.84 & -0.81 & 0.34 & -0.06 & 4.0 & 7.9 \\
\hline
\end{tabular}

Data are presented as altitude in kilometres above sea level. Sex was coded 0 for females and 1 for males. BMI: body mass index; FEV 1 : forced expiratory volume in one second; \% pred: percentage of that predicted by HANKINSON et al. [15]; MSE: mean square error. * : Coefficients for age, BMI and FEV1 (\% pred) are expressed for a 10unit change. Using barometric pressure instead of altitude did not improve the fit of the equation. $"$ : Proposed equation that allows interpolating predicted results for other altitudes, assuming a linear change with altitude. Resulting coefficients for the mean altitude of the cities obtained from the last equation differ slightly from the first three because it is weighted by all data and also because altitude varies in Mexico City and Caracas. 
exercise should also receive oxygen, even if the resting $\mathrm{SP}, \mathrm{O}_{2}$ is $>88 \%$. However, domiciliary oxygen therapy in subjects with $\mathrm{Pa}_{1} \mathrm{O}_{2} 60-70 \%$ or with nocturnal desaturation did not increase survival $[19,20]$ and, therefore, is a secondary priority for home oxygen services.

Pulse oximeter measurements have good correlation with the gold standard for oximetry in arterial blood samples [21]. Although pulse oximeters cannot separate oxyhaemoglobin from carboxyhaemoglobin, $\mathrm{SP}, \mathrm{O}_{2}$ measurements made with pulse oximeters correlate well with saturation of haemoglobin available for gas exchange, even in Mexico City [21], where levels of carboxyhaemoglobin of $1.6 \%$ were reported in nonsmokers [22], but can increase several times in smokers. In the present study, although a measurement of carboxyhaemoglobin was lacking, the addition of an indicator of current smoking did not add explaining power to the regression models. The prediction equations based on population samples could be useful to estimate distribution of $\mathrm{Sa}_{1} \mathrm{O}_{2}$ and hypoxaemia $\left(\mathrm{SP}, \mathrm{O}_{2} \leqslant 88 \%\right)$ as a function of altitude, age, $\mathrm{BMI}$, and FEV1. However, the regression models explained only a third of $\mathrm{SP}, \mathrm{O}_{2}$ variability and approximately a quarter of oxygen desaturation, which reinforces the need to measure $S \mathrm{P}, \mathrm{O}_{2}$ and demonstrates the limited understanding of hypoxaemia in populations. Part of this unexplained variation could be reduced with arterial blood gases, but these will be difficult to obtain in population-based samples. Also, better estimates can be expected if population data from cities with altitudes other than those studied are included.

It is important to emphasise that this is a cross-sectional study. Subjects $>75$ yrs of age had a similar $\mathrm{SP}_{2} \mathrm{O}_{2}$ to subjects aged $65-$ 70 yrs. In previous studies, $\mathrm{Pa}_{\mathrm{a}} \mathrm{O}_{2}$ also did not decrease with age in subjects $>70$ yrs [23-25]. This is likely to represent a cohort effect, with survivors, and it does not mean that a person of 65 yrs of age should expect a constant $\mathrm{SP}, \mathrm{O}_{2}$ in subsequent years.

The present authors were able to obtain a minimum questionnaire in rejecters, showing that males and the elderly tended to refuse more often than females and younger people, and that the rate of smoking was similar in participants and nonparticipants. This suggests that the reason for refusals was not related to lung disease.

It is necessary to know the impact of hypoxaemia in Mexico City and other cities at similar altitude, in order to properly define the criteria for prescribing oxygen. Currently, the present authors use the criteria that demonstrated improved survival at sea level in subjects with advanced COPD [3-5, 9]. The present authors demonstrated an adverse impact of $S P, \mathrm{O}_{2} \leqslant 88 \%$ on the physical scale of the SF-12 ${ }$ questionnaire even after adjusting by altitude, sex, age, FEV1 and BMI and level of education. This supports the validity of the current definition of hypoxaemia not only close to the sea level but also at higher altitudes. This perhaps supports the current criteria for home oxygen even at altitude. However, information is needed on the long-term impact of hypoxaemia at moderate altitudes on a variety of health indicators, including mortality, quality of life, neuropsychological functioning, pulmonary artery pressure, cardiac function and level of haemoglobin, at least until other indicators of tissue hypoxia are available.
Hypoxia is the highest threat to aerobic organisms and, although residence at altitude is likely to have decreased the impact of the so-called "tropical diseases" for centuries, hypoxaemia due to residing at moderate altitudes could now represent a health risk compared with living at sea level.

In conclusion, oxygen desaturation was observed in $6 \%$ of the inhabitants of Mexico City and 1\% of inhabitants of Caracas aged $>40$ yrs, but in none of the inhabitants of Montevideo. Only $8 \%$ of hypoxaemic subjects in Mexico City and Caracas were using arterial oxygen saturation $\leqslant 88 \%$, as measured by pulse oximetry. It is unfeasible to provide home oxygen to $6 \%$ of the adult population of Mexico City and, therefore, criteria to prescribe home oxygen more rationally are urgently required.

\section{ACKNOWLEDGEMENTS}

The Proyecto Latinoamericano de Investigacion en Obstruccion Pulmonar (PLATINO) group for this project was formed by E. Chávez-Plascencia, J.C. Vázquez-García, A. Corcho-Berdugo, F. Franco-Marina and D. Moreno.

\section{REFERENCES}

1 Pierson DJ. Pathophysiology and clinical effects of chronic hypoxia. Respir Care 2000; 45: 39-51.

2 MacNee W. Pathophysiology of cor pulmonale in chronic obstructive pulmonary disease. Part one. Am J Respir Crit Care Med 1994; 150: 833-852.

3 Anthonisen NR. Long-term oxygen therapy. Ann Intern Med 1983; 99: 519-527.

4 British Medical Research Council Working Party. Long term domiciliary oxygen therapy in chronic hypoxic cor pulmonale complicating chronic bronchitis and emphysema. Lancet 1981; 1: 681-686.

5 Nocturnal Oxygen Therapy Trial Group. Continuous or nocturnal oxygen therapy in chronic obstructive lung disease: a clinical trial. Ann Intern Med 1980; 93: 391-398.

6 Janssens JP, Pache JC, Nicod LP. Physiological changes in respiratory function associated with ageing. Eur Respir J 1999; 13: 197-205.

7 Koenig SM. Pulmonary complications of obesity. Am J Med Sci 2001; 321: 249-279.

8 Pérez-Padilla R. Population distribution residing at different altitudes: implications for hypoxemia. Arch Med Res 2002; 33: 162-166.

9 Pauwels RA, Buist AS, Calverley PM, Jenkins CR, Hurd SS, GOLD Scientific Committee. Global strategy for the diagnosis, management, and prevention of chronic obstructive pulmonary disease. NHLBI/WHO Global Initiative for Chronic Obstructive Lung Disease (GOLD) Workshop summary. Am J Respir Crit Care Med 2001; 163: 1256-1276.

10 Hungin AP, Chinn DJ, Convery B, Dean C, Cornford CS, Russell A. The prescribing and follow-up of domiciliary oxygen - whose responsibility? A survey of prescribing from primary care. Br J Gen Pract 2003; 53: 714-715.

11 Menezes AM, Victora CG, Perez-Padilla R. The Platino project: methodology of a multicenter prevalence survey of chronic obstructive pulmonary disease in major Latin American cities. BMC Med Res Methodol 2004; 4: 15. 
12 Menezes AMB, Perez-Padilla R, Jardim JRB, et al. Chronic obstructive pulmonary disease in five Latin American cities (the PLATINO study): a prevalance study. Lancet 2005; 366: 1875-1881.

13 Habicht JP. Estandarización de métodos epidemiológicos cuantitativos sobre el terreno. [Standardisation of quantitative epidemiological methods in the field.]. Boletín de la Oficina Sanitaria Panamericana 1974; 76: 375-381.

14 American Thoracic Society. Standardization of spirometry. 1994 update. Am J Respir Crit Care Med 1995; 152: 1107-1136.

15 Hankinson JL, Odencrantz JR, Fedan KB. Spirometric reference values from a sample of the general U.S. population. Am J Respir Crit Care Med 1999; 159: 179-187.

16 Beall CM, Almasy LA, Blangero J, et al. Percent of oxygen saturation of arterial hemoglobin among Bolivian Aymara at 3,900-4,000 m. Am J Phys Anthropol 1999; 108: 41-51.

17 Gandek B, Ware JE, Aaronson NK, et al. Cross-validation of item selection and scoring for the SF-12 Health Survey in nine countries: results from the IQOLA Project. International Quality of Life Assessment. J Clin Epidemiol 1998; 51: 1171-1178.

18 Ward MP, Milledge JS, West JB. High Altitude Medicine and Physiology. Philadelphia, University of Pennsilvania Press, 1989; p. 55.

19 Fletcher EC, Luckett RA, Goodnight-White S, Miller CC, Qian W, Costarangos-Galarza C. A double-blind trial of nocturnal supplemental oxygen for sleep desaturation in patients with chronic obstructive pulmonary disease and a daytime $\mathrm{PaO}_{2}$ above $60 \mathrm{mmHg}$. Am Rev Respir Dis 1992; 145: 1070-1076.

20 Crockett AJ, Cranston JM, Moss JR, Alpers JH. Domiciliary oxygen for chronic obstructive pulmonary disease. Cochrane Database Syst Rev 2000; 4: CD001744.

21 Perez-Padilla JR, Bracamonte-Peraza R, Manrique G, RuizPrimo ME. Accuracy of the ear oximeter Box-III and its sensitivity to carboxyhemoglobin in Mexico City. Arch Inst Cardio Mex 1986; 56: 303-307.

22 Cicero R, Becerril G, Ramírez E, Salinas F. Niveles de carboxihemoglobina en sujetos no fumadores y fumadores de dos ciudades del altiplano mexicano. [Levels of carboxyhemoglobin in smokers and non-smokers from two cities of the Mexican high plateaux.]. Rev Inv Clin 1991; 43: 40-44.

23 Hardie JA, Vollmer WM, Buist AS, Ellingsen I, Morkve O. Reference values for arterial blood gases in the elderly. Chest 2004; 125: 2053-2060.

24 Guenard H, Marthan R. Pulmonary gas exchange in elderly subjects. Eur Respir J 1996; 9: 2573-2577.

25 Cerveri I, Zoia MC, Fanfulla F, et al. Reference values of arterial oxygen tension in the middleaged and elderly. Am J Respir Crit Care Med 1995; 152: 934-941. 